\title{
Motivational teacher strategies: the role of beliefs and contextual factors
}

\author{
Lisette Hornstra $^{1,2}$ - Caroline Mansfield ${ }^{3}$ Ineke van der Veen ${ }^{4}$. \\ Thea Peetsma ${ }^{1} \cdot$ Monique Volman $^{1}$
}

Received: 22 December 2012/ Accepted: 14 May 2014/Published online: 22 July 2015

(C) The Author(s) 2015. This article is published with open access at Springerlink.com

\begin{abstract}
Teachers are key actors who shape the learning environment and whose main tasks include motivating students to learn. Teachers can differ in the way in which they try to motivate students to learn and their motivational strategies can vary from autonomysupportive to controlling. The present study explored how teachers' personal beliefs and contextual factors relate to their self-reported autonomy-supportive or controlling motivational strategies. Nine grade six teachers at schools with varying student populations were interviewed. Based on their self-reported motivational strategies, two clusters of teachers were distinguished: teachers who mainly reported autonomy-supportive strategies and teachers who mainly reported controlling motivational strategies. The strategies of autonomy-supportive teachers aligned well with their personal beliefs and preferences, whereas some teachers in the controlling cluster would prefer more autonomy-supportive strategies. Underlying reasons for more controlling teaching strategies were mainly contextual, including 'factors from above' such as national standards or high-stakes testing, but mainly 'factors from below' referring to negative perceptions of students' abilities, behaviour, background characteristics or motivation. Implications are drawn and suggestions for further research are provided.
\end{abstract}

Keywords At-risk students - Learner autonomy · Learning environment · Student motivation - Teacher beliefs - Teacher expectations of students . Teaching strategies

Lisette Hornstra

T.E.Hornstra@uu.nl

1 Research Institute of Child Development and Education, PO Box 15780, 1001 NG Amsterdam, The Netherlands

2 Utrecht University, Faculty of Social and Behavioral Sciences, PO Box 80140, 3508 TC Utrecht, The Netherlands

3 School of Education, Murdoch University, Murdoch, WA 6150, Australia

4 Kohnstamm Institute, Plantage Muidergracht 24, 1018 TV Amsterdam, The Netherlands 


\section{Introduction}

It is increasingly recognised that the learning environment is an important factor in explaining students' motivation for school and their learning outcomes (Eccles and Roeser 2011; Pintrich 2004). Teachers are key actors who shape the learning environment (Eccles and Roeser 2011) and one of their most important tasks is to create a learning environment that enhances and sustains students' motivation and engages students in learning. The present study focused on the extent to which teachers' motivational strategies are autonomy-supportive versus controlling, and on the reasons underlying teachers' motivational strategies. In this study, the term motivational strategies refers to all teaching strategies aimed at encouraging students' learning. This term also refers to those strategies that motivate students by pressuring them. Such controlling strategies might not appeal to students' intrinsic or autonomous motivation, but instead to students' controlled motivation (e.g. Ryan and Deci 2000a).

According to Self-Determination Theory (SDT; Deci and Ryan 1985; Ryan and Deci 2000b), students have three basic innate needs: to feel related to others, to feel competent and to feel autonomous. The provision of involvement by teachers can foster students' need for relatedness and the provision of structure (e.g. providing clear guidelines) can foster students' need for competence (Stroet et al. 2013). This study specifically focused on teaching strategies that are aimed at supporting students' need to feel autonomous. Even though previous literature suggests that autonomy-supportive motivational strategies foster students' intrinsic motivation (Niemic and Ryan 2009; Stroet et al. 2013; Vansteenkiste et al. 2004), studies in various countries have demonstrated that many teachers rely on controlling strategies instead using extrinsic rewards and punishments to encourage learning (Pelletier et al. 2002; Reeve et al. 2004a, b; Turner 2010; Turner et al. 2009). The finding that many teachers rely on controlling strategies can partly be explained by teachers' underlying personal beliefs about what motivates students or their preferences towards a certain teaching style, but previous literature has also indicated that contextual conditions, such as school regulations, national standards or high-stakes testing, can pressure teachers towards controlling motivational strategies (Reeve 2009). These have been referred to as 'factors from above' (Pelletier et al. 2002). Additionally, teachers' motivational strategies also can be affected by 'factors from below' referring the particular characteristics of their classroom population. Teacher expectancy literature (Rosenthal 1994) has shown that teacher perceptions of their students' ability or background can affect many aspects of teaching and learning outcomes. Even so, little research has examined how teacher perceptions of their students relate to the type of motivational strategies that teachers believe to be effective and consequently adopt in their classrooms.

Given the importance of teachers' motivational strategies for students' motivation and learning outcomes, the purpose of this small-scale exploratory study was to gain more insight into how teachers negotiate their personal beliefs with contextual factors, and how this affects the extent to which they adopt autonomy-supportive or controlling teaching strategies. As such, this paper contributes to our understanding of why teachers often rely on controlling motivational strategies even though these controlling strategies have been associated with adverse student outcomes. 


\section{Autonomy-support versus control}

According to Self-Determination Theory (SDT; Deci and Ryan 1985), motivational strategies can vary along a continuum that ranges from highly autonomy-supportive to very controlling (Deci et al. 1991; Ryan and Deci 2000a; Vallerand 1997; Vansteenkiste et al. 2004). Autonomy-supportive motivational strategies aim to nurture students' inner motivational resources and volitional intentions to act. In classrooms, autonomy can be facilitated by transferring responsibility of the learning process to students, providing choice, connecting to students' interests, providing explanatory rationales, and creating meaningful and relevant learning activities. Such strategies are aimed at increasing students' own willingness to engage in learning activities. Conversely, controlling motivational strategies include compelling students to think, feel or act in certain ways, and overruling students' own perspectives. Controlling teachers motivate students by external incentives, pressure or control instead of relying on students' inner motivational resources. Such strategies include the use of external rewards such as grades or directive language (Jang et al. 2010; Niemic and Ryan 2009; Reeve and Jang 2006; Reeve et al. 2004a, b; Vansteenkiste et al. 2004). Although it is often assumed that autonomy-supportive strategies and structure are opposites, structure can be delivered in autonomy-supportive ways (Reeve 2009) by communication of clear expectations, giving directions, providing guidelines and setting limits. Control is different from structure, however, because control implies that teachers exert pressure on students (Reeve 2009).

Autonomy-supportive teaching strategies have been associated with higher intrinsic motivation and more favourable learning outcomes (Jang et al. 2010; Reeve et al. 2004a, b; Ryan and Deci 2000b; Vansteenkiste et al. 2004, 2006). Autonomy-supportive teaching in combination with structure has been found to be most beneficial to students' motivation (Sierens et al. 2009). Likewise, research from interpersonal theory has demonstrated that teaching styles characterised by high affiliation with students in combination with intermediate levels of control are associated with higher levels of student motivation (Wubbels and Brekelmans 2005). Moreover, various studies have indicated that constructivist teaching approaches which include elements of autonomy-supportive teaching, such as personal relevance, shared control and student negotiation, positively relate to student motivation (e.g. Fraser 2012; Henderson and Fisher 2008; Maulana et al. 2012; Ogbuehi and Fraser 2007). In contrast, high levels of dominance or control have been associated with adverse motivational outcomes, such as lower intrinsic motivation, more controlled motivation, or even lack of motivation (Jang et al. 2010; Reeve et al. 2004a, b; Ryan and Deci 2000a; Vansteenkiste et al. 2004, 2006; Wubbels and Brekelmans 2005).

Many studies have shown that, in practice, teachers often use controlling motivational strategies even though research seems to indicate that autonomy-supportive strategies are more favourable with regard to students' motivation (e.g. Reeve 2009; Stroet et al. 2013; Turner 2010). Thus far, many studies on teachers' motivational strategies have depended on survey research (Stroet et al. 2013). However, the choice to use controlling or autonomy-supportive teaching strategies and their effectiveness could depend on a variety of factors often not taken into account in survey research, such as teachers' personal beliefs, contextual factors and student characteristics (Furtak and Kunter 2012; Iyengar and Lepper 1999). To gain more insight into these aspects, the present study therefore qualitatively examined the role of teachers' personal beliefs and the contextual factors that teachers can experience in relation to their motivational strategies. 


\section{Teachers' personal beliefs and their motivational strategies}

Teachers usually hold very stable long-term beliefs about the nature of student motivation and the particular motivational strategies that are effective in motivating their students (Pajares 1992; Turner 2010; Turner et al. 2009). Teacher beliefs are developed through teachers' own experiences as learners (Mansfield and Volet 2010; Richardson 2003), their initial teacher training (Avalos 2011; Mansfield and Volet 2010; Richardson 2003), as well as their professional experiences as teachers (Avalos 2011; Turner et al. 2009).

Often, teachers use controlling motivational strategies that can be at odds with motivational theories (Reeve 2009; Turner 2010). Several reasons can account for this difference between motivational theory and actual teacher behaviours. Teachers' personal beliefs about motivation and learning or their role as a teacher can account for some differences (Eisenhart et al. 1988). Teachers can find controlling strategies more effective when they seem to believe that students are not motivated. In such instances, teachers consider lack of motivation to be an innate characteristic of students, and they might resort to controlling strategies so that they can make students work without having to encourage their inner motivational resources (Reeve 2009). Furthermore, a teacher's belief that extrinsic rewards encourage learning can be deeply rooted and so, when students are not autonomously motivated, teachers could offer extrinsic rewards such as grades to make students learn. Also, some teachers could feel that they will more efficiently reach their instructional goals when using controlling strategies (Reeve 2009). In other words, simply instructing students about what to do, instead of explaining the relevance or providing choice through offering different strategies, seems to be less time consuming for teachers. Previous research has also shown that teachers' motivational strategies do not always correspond with their own motivational beliefs (Mansour 2009; Raymond 1997). Some teachers could have personal beliefs favouring autonomy-supportive motivational strategies, but there could be factors in the educational context that constrain teachers from teaching according to those beliefs (Mansour 2009).

\section{Teachers' perceptions of contextual pressures and their motivational strategies}

Pelletier et al. (2002) described several contextual conditions that can pressure teachers to teach in controlling ways. Contextual factors can be divided into factors from above and factors from below. Factors from above, with which teachers in many countries are faced, include performance standards (Deci et al. 1982), high-stakes testing (Nolen 2011; Ryan and Brown 2005; Ryan and Weinstein 2009) or pressure from school administrations, colleagues and parents (Reeve 2009). In contrast, factors from below arise from the day-today interactions within the classroom and refer to the motivational characteristics of the student population (Pelletier et al. 2002). Pelletier et al. (2002) found that teachers resorted to more extrinsically-oriented controlling motivational strategies when students appeared unmotivated. When perceiving a lack of intrinsic motivation from students, teachers might try to tell students what to do or motivate them by grades or other forms of rewards or punishments. Furthermore, Oakes (1985) found that teachers in schools with many lowachieving students emphasised controlling motivational strategies, conformity and obedience. Likewise, Solomon et al. (1996) found that teachers who worked at more disadvantaged schools rated their strategies as more controlling, held more positive attitudes towards teacher authority and held less positive attitudes towards student autonomy. 
Other than the aforementioned studies, few SDT studies have taken teacher perceptions of the student population into account, but previous research on teacher expectancies has shown that teacher perceptions of individual students are indeed very powerful in shaping teaching behaviours and subsequent learning outcomes (Jungbluth 2003; Jussim and Harber 2005; McKown and Weinstein 2008; Nurmi et al. 2012; Rosenthal and Jacobson 1968; van den Bergh et al. 2010). Important sources that shape teacher perceptions are students' ability levels (Madon et al. 1997), social background (Jussim et al. 1996) and ethnic background (Tenenbaum and Ruck 2007; van den Bergh et al. 2010). In many Western countries, teachers are faced with diverse student populations in terms of abilities and background (Bakker and Denessen 2011) and perceptions of these characteristics can cause differential teacher behaviours. For example, teachers have been found to show less warmth towards students for whom they hold low expectations, give fewer opportunities to respond, and provide less feedback, which in turn can result in lower achievement (Rosenthal 1994). Tenenbaum and Ruck (2007) furthermore showed that teacher behaviours towards students from different ethnic groups differed significantly with teachers being more friendly and encouraging towards European-American students than towards ethnic minority students. A recent study by Nurmi et al. (2012) showed that teachers were more actively involved with low-achieving students, providing more structure to guide their learning. Teacher perceptions of these student characteristics can not only affect their interpersonal behaviours towards different students in their class, but it seems likely that they also affect the extent to which teachers use autonomy-supportive or controlling strategies.

Moreover, SDT theory has mainly focused on whole-classroom strategies, while most teacher expectancy studies have focused on within-classroom differences and subsequent differential teacher strategies of teachers towards low-expectancy versus high-expectancy students (Rubie-Davies 2010). Both whole-classroom strategies and teacher responses to individual students affect student motivation and achievement. Focusing on both individual and whole-classroom teacher strategies enables a deeper understanding of reasons underlying teachers' strategies. Recently, two studies of teacher expectancies involved how whole-classroom characteristics affect teachers' instructional strategies, showing that teacher perceptions of classroom characteristics affect use of extrinsically-oriented or intrinsically-oriented motivational strategies (Rubie-Davies et al. 2012) and students' learning outcomes (Archambault et al. 2012). These studies suggest that autonomy-supportive or controlling motivational strategies indeed can depend on teachers' perceptions of the whole classroom in addition to perceptions of and subsequent strategies towards individual students.

Other than these studies, few studies have examined how teachers' controlling versus autonomy-supportive motivational strategies are affected by their perceptions of their whole classroom and of individual students. If teachers' motivational strategies are dependent on their perceptions of the classroom, and teachers in perceived 'at-risk' classrooms resort to more controlling strategies to motivate their students, they actually could be undermining students' intrinsic motivational resources. As such, already-existing differences in motivation and learning outcomes actually might be exacerbated.

\section{Research questions}

To explore the reasons behind teachers' self-reported motivational strategies, the following research questions were addressed: 
1. What types of motivational strategies do teachers report?

2. What are teachers' personal beliefs towards autonomy-supportive and controlling motivational strategies and how do these vary for teachers with different self-reported motivational strategies?

3. What factors from below do teachers experience and how do these vary for teachers with different self-reported motivational strategies?

4. What factors from above do teachers experience and how do these vary for teachers with different self-reported motivational strategies?

\section{Method}

\section{Participants}

Nine grade six teachers (six female, three male) from different primary schools across the Netherlands participated. Pseudonyms are used in this paper. Grade six is the final year of primary school and students are 11-12 years old. The average age of the participating teachers was 40 years and ranged from 25 to 57 . On average, they had 12 years of teaching experience, ranging from 2 to 34 years. The teachers were selected from a sample of 37 teachers participating in a larger quantitative study about innovative teaching methods. Selection of teachers for interviews was based on self-report questionnaires with the intention that the sample would represent maximum variation from teachers who used mostly innovative to mostly traditional teaching methods. Using these questionnaires, teachers indicated the level of innovativeness of their teaching methods (e.g. collaborative learning, processoriented instruction, and authenticity of the learning environment) on five-point Likert scales. Scores on these subscales were averaged and ranged from 2.9 to 4.6. Table 1 presents an overview of the characteristics of the teachers, classes and schools. The scores on innovative learning were only used to create a sample with maximum variety in teaching methods and were not taken into account in further analyses. Aspects of innovative teaching do not necessarily imply that teachers teach in more autonomy-supportive ways. Although innovative learning allows a more autonomy-supportive motivational style, these aspects (e.g. collaborative learning) could also be delivered in a controlling way. To illustrate this point, Jane had the highest questionnaire scores, but many of her self-reported motivational strategies (as becomes apparent later on in the paper) were controlling. For example, she indicated a high degree of cooperative learning on the questionnaire, but in the interview she expressed that her students are motivated to work during group work, because they are held accountable afterwards, instead of the group work and responsibility in itself being motivating:

We work a lot with cooperative tasks.... And all students know that they can get the question afterwards (Jane).

Even though schools in the Netherlands vary in level of innovativeness, all schools are held to national standards and use national standardised tests (developed by the Central Institute for Test Development, CITO). In grade 6, students take a final CITO test that weighs heavily in determining the track to which students will be referred (Driessen et al. 2008). This test can be considered high stakes because students' educational futures are largely dependent on the outcomes of these tests and outcomes weigh heavily in how the inspectorate judges quality of schools. The participating schools furthermore varied in their social and ethnic classroom composition, which is typical for the Dutch educational system. 
Table 1 Teacher, class and school characteristics

\begin{tabular}{|c|c|c|c|}
\hline Teacher & Background characteristics of school & $\begin{array}{l}\text { Number of } \\
\text { students in } \\
\text { the class }\end{array}$ & $\begin{array}{l}\text { Self-reported level } \\
\text { of innovativeness } \\
\text { (scale 1-5) }\end{array}$ \\
\hline Cathy (female, 31) & $\begin{array}{l}\text { Public school in a large town; the school } \\
\text { population consists of only ethnic } \\
\text { minority students, almost all with low } \\
\text { SES. The inspectorate judged the school } \\
\text { as 'very weak' during multiple } \\
\text { inspections, and forced the school to } \\
\text { close. The school year in which the } \\
\text { interviews were held was the last year } \\
\text { before closure }\end{array}$ & $\begin{array}{l}10 \text { (+around } \\
8 \text { grade } 5 \\
\text { students) }\end{array}$ & 2.9 \\
\hline Bert (male, 50) & $\begin{array}{l}\text { Christian school. The school was originally } \\
\text { a Jenaplan school but decided to change } \\
\text { to more traditional teaching methods. The } \\
\text { school is in a neighbourhood that is } \\
\text { known to be a bit disadvantaged. Mostly } \\
\text { medium SES students. There are about } \\
10 \% \text { ethnic minority students }\end{array}$ & 24 & 3.0 \\
\hline Rachel (female, 35) & $\begin{array}{l}\text { Public school in a small town. The } \\
\text { population consists of mostly low SES } \\
\text { students and around } 40 \% \text { ethnic minority } \\
\text { students. The inspectorate judged the } \\
\text { school as 'weak' during the last } \\
\text { inspection }\end{array}$ & 14 & 3.1 \\
\hline Tom (male, 29) & $\begin{array}{l}\text { Protestant school in a small to middle-sized } \\
\text { town. SES of the students is mostly } \\
\text { medium or high, few ethnic minority } \\
\text { students }\end{array}$ & 20 & 3.9 \\
\hline Sam (male, 38) & $\begin{array}{l}\text { Public school in the centre of a middle- } \\
\text { sized town. SES of the students is mostly } \\
\text { medium to high, few ethnic minority } \\
\text { students }\end{array}$ & 28 & 4.1 \\
\hline Gemma (female, 55) & $\begin{array}{l}\text { Public school in a small town, it is in a } \\
\text { trajectory to become a BAS school } \\
\text { (building an adaptive school). The school } \\
\text { has mostly low and medium SES students. } \\
\text { There are no ethnic minority students }\end{array}$ & 24 & 4.2 \\
\hline Anne (female, 25) & $\begin{array}{l}\text { Catholic school in a larger town. The school } \\
\text { is in progress of becoming a Dalton } \\
\text { school. Population consists of students of } \\
\text { low, medium and high SES. There are a } \\
\text { few ethnic minority students attending } \\
\text { this school }\end{array}$ & $\begin{array}{l}17 \text { (+around } \\
10 \text { grade } 5 \\
\text { students) }\end{array}$ & 4.3 \\
\hline Ella (female, 57) & $\begin{array}{l}\text { Protestant school in a middle sized town. } \\
\text { Jenaplan school. Mostly high SES } \\
\text { students, some average SES students }\end{array}$ & 24 & 4.4 \\
\hline Jane (female, 36) & $\begin{array}{l}\text { Catholic school in a small town. The school } \\
\text { consists of students of low, medium and } \\
\text { high SES and very few ethnic minority } \\
\text { students }\end{array}$ & 31 & 4.6 \\
\hline
\end{tabular}




\section{Interviews}

A single semi-structured in-depth interview was conducted with each teacher. The advantage of using interviews for this study was that it could provide a deeper understanding of the beliefs underlying teachers' motivational strategies and the contextual factors that they experienced. Halfway through the school year, teachers were interviewed at their own schools by either the main researcher or a trained research assistant. Interviews lasted 45-60 $\mathrm{min}$.

To initially get a general idea of the strategies that teachers employed in their classes, teachers were presented with several vignettes describing schools with varying teaching methods ranging from traditional to innovative (the vignettes are described in "Appendix"). After being presented with the vignettes, teachers were asked whether their strategies corresponded more to the traditional or innovative teacher or somewhere in between. Although innovative methods often allow more autonomy-supportive strategies, that is not necessarily always the case. For example, with collaborative learning, teachers can be very autonomy-supportive, but also collaborative learning can also be brought about in controlling ways by telling students exactly what they should do or by offering extrinsic rewards. These vignettes were therefore just used as a starting point to elicit responses regarding why and how they used certain methods, and how they believed that their strategies affected student motivation (e.g. 'How often do students work together?', 'How do you organise them working together?', 'What instructions do you give?', 'How do your students respond?', 'How does working together affect their motivation?'). Teachers were encouraged to give explanations and examples. Furthermore, questions aimed at beliefs about motivating students were asked (e.g. 'What do you think is motivating to students?', 'What are strategies do you believe motivate your class?'). These questions were often followed by follow-up questions about their strategies to examine to what extent beliefs and strategies aligned or differed ['Do you do this in your class?' 'Why (not)?']. The vignettes and these questions about motivating students explored the extent to which teachers' motivational strategies for the whole class and towards individual students ranged from controlling to autonomy-supportive, as well as their beliefs and reasons behind their strategies. In follow-up questions, reasons behind teachers' motivating beliefs and strategies were addressed. This was first asked generally ('What are reasons for you to use this approach?') and this was followed by more specific questions about factors from above (the schools' educational concept, school administration and formal regulations) and factors from below (teachers' perceptions of their student population). We focused on teacher perceptions of the student population, rather than on objective information about classroom composition, because teachers' views of their students probably affect their decision-making process more than actual classroom characteristics. Next, questions with regard to beliefs about motivating specific students were asked ('Can you describe a student who you feel is very motivated?' 'How do you try to keep this student motivated?', 'Can you describe a student who is difficult to motivate?', 'How do you try to keep this student motivated?').

\section{Analysis}

All interviews were transcribed, conducted in Dutch and analysed in Dutch. First, units of meanings (referred to as statements) were distinguished, referring to a consistent theme or idea. This could be a few words or a single sentence, but also various sentences that formed 
a chain of arguments. Each statement was given a code, using a content analysis approach (Miles and Huberman 1994). First, all units were coded into six broad target concepts: (1) self-reported motivational strategies, (2) personal beliefs or preferences, (3) factors from above, (4) perceptions of the student population, (5) factors from below (relations between perceptions of student population and motivational strategies) and (6) other. Personal beliefs and preferences were coded in one category, because they included more general beliefs about what 'works' to motivate students as well as personal preferences towards autonomy-support or control. Data in the category 'other' were not taken into account in further analysis. Next, all statements were coded into the subcategories listed in Table 2. Teachers' self-reported motivational strategies were further coded as either autonomysupportive, controlling or other. Statements indicative of transferring responsibility of the learning process to students, providing choice, connecting to students' interests, providing explanatory rationales and creating meaningful and relevant learning activities - in other words, strategies are aimed at increasing students' own willingness to engage in learning activities - were coded as autonomy-supportive. Statements were coded as controlling when teachers indicated that they motivated their students by external incentives, pressure or control, such as the use of external rewards such as grades or directive language. Strategies were coded as other when self-reported strategies appeared to be in between control and autonomy-support, contained aspects of both types of strategies, or when a statement did not contain enough information to be certain about whether the practice was controlling or autonomy-supportive. Likewise all statements referring to personal beliefs or preferences were coded into subcategories with personal beliefs being either autonomysupportive, controlling or coded as other. When teachers mentioned factors that affected their strategies, these were coded either as 'factors from above' or 'factors from below'.

Table 2 Final coding scheme

\begin{tabular}{ll}
\hline Target concepts & Subcategories \\
\hline Self-reported motivational strategies & Autonomy-supportive motivational strategies \\
& Controlling motivational strategies \\
& Other \\
Personal beliefs or preferences & Beliefs towards autonomy-supportive motivational strategies \\
& Beliefs towards controlling motivational strategies \\
& Other \\
Factors from above (when mentioned & National performance standard/inspectorate \\
that these affect strategies) & High-stakes testing \\
& School administration \\
& Textbook methods used at the school \\
& Pressure from parents \\
& Other contextual factors from above (logistics, time \\
& management) \\
Perceptions of the student population & Statements related to at-risk characteristics (low ability, \\
& disadvantaged/ethnic-minority backgrounds, difficult \\
behaviour, low motivation) \\
that these affect strategies) & Neutral/average comments about students \\
& Statements related to high ability, motivation, good behaviour \\
& or high social background \\
& Differential perceptions (focus on within-group differences) \\
& Whole-class characteristics \\
& Individual students \\
\hline
\end{tabular}


Factors from above refer to factors outside the classroom that affected teachers' strategies and include for example national performance standards, or the school administration. Statements that referred to perceptions of the student population without describing how these perceptions affected strategies were coded as 'perceptions of student population'. Factors from below were coded when teachers mentioned characteristics of their student population as a reason for their strategies. These categories and all further subcategories are listed in Table 2.

The first author and a trained research assistant who also conducted some of the interviews both coded two interviews independently. Full agreement was initially reached on $64 \%$ of individual codes. The statements for which full agreement was not reached were discussed. Disagreements were mostly found when it was unclear whether a statement was about a practice or about a belief, such as the statement below:

What appealed to me about this new concept that we now use is the cooperation between students (Gemma).

It was agreed that such statements would be coded in both categories. Also inconsistencies arose with some statements referring to providing structure. It was not always clear whether the way of providing structure was controlling or not. These statements were reexamined and compared to definitions from control and autonomy from the literature and it was discussed what would be coded as control and what would be coded as autonomysupport. These statements were then independently recoded. Full agreement was then reached on $76 \%$ of statements. After examining and discussing disagreements again and refining the coding scheme further, another interview was then independently coded by both coders and final inter-coder agreement on this interview was $86 \%$. The first author then recoded the initial two interviews and the remaining interviews accordingly. Table 2 provides the final coding scheme.

To answer the research questions, the number of statements that referred to self-reported autonomy-supportive and controlling strategies were examined. Based on the percentage of autonomy-supportive and controlling strategies reported by each teacher, two distinct clusters of teachers were identified (the clustering is further explained in the results section). Thereafter, these two clusters of teachers with distinct strategies were compared with regard to their beliefs, the contextual factors that they experienced, and how these beliefs and factors affected their self-reported motivational strategies.

\section{Results}

\section{What types of motivational strategies do teachers report?}

A total of 159 statements (13-27 statements per teacher) referred to teachers' self-reported motivational strategies. Statements indicative of transferring responsibility of the learning process to students, providing choice, connecting to students' interests, providing explanatory rationales and creating meaningful and relevant learning activities were coded as autonomy-supportive. This was the case for $30 \%(n=47)$ of the statements referring to self-reported motivational strategies. A similar proportion of statements, $31 \%(n=50$ statements) were coded as controlling and included statements in which teachers indicated that they motivated their students through external incentives, pressure or control. Statements that did not clearly belong to either category (39 \%, $n=62)$ were coded as 'other' and were most frequent. All teachers reported strategies that were coded as 'other', and this 
varied from $23 \%$ of statements to $54 \%$ of statements. This category contained statements that were in between or formed a combination of autonomy-support and control, or did not contain enough information to code them as either autonomy-supportive or controlling, for example "It is not like I don't give them instruction, or I don't have moments when I'm in front of the class, because I do" (Gemma). In this example referring to Gemma's strategies, it is not clear whether Gemma teaches in a controlling or autonomy-supportive way when she is in front of the class. The percentage of controlling and autonomy-supportive statements per teacher is displayed in Fig. 1. The table below Fig. 1 also displays the percentages of motivational strategies coded as 'other'.

When comparing the number of statements referring to autonomy-supportive or controlling strategies, two clusters of teachers could be distinguished. The first cluster is made up of teachers who reported more controlling than autonomy-supportive statements. This cluster ('Controlling') includes the teachers Bert, Cathy, Rachel and Jane (the four teachers on the left in Fig. 1). The second cluster is made up of teachers who reported more autonomy-supportive than controlling statements. This cluster ('Autonomy-supportive') contains Ella, Gemma, Anne, Tom and Sam. In the paper, teachers from the two clusters are referred to as controlling or autonomy-supportive teachers, but it is important to note that these clusters refer not to different types of teachers with stable teaching styles, but to teachers who differed in their self-reported strategies at the time of the interview, with their particular class and in a particular context. These strategies most likely arise from teachers' personal beliefs, as well as from interactions with the context, and can therefore not be generalised to other contexts.

As expected, there was variation within the clusters. Bert from the controlling cluster was a clear example of a consistently controlling teacher, who explained that his students have to do as they are told. Cathy and Rachel also reported a majority of controlling strategies but, unlike Bert, they also reported some autonomy-supportive strategies. Finally, Jane was also classified as controlling, because she reported more controlling than autonomy-supportive strategies, but most statements by Jane were classified as 'other' and were often in between autonomy-supportive and controlling strategies. Variation was also found in the autonomy-supportive cluster. Sam did not mention any controlling strategies, whereas the other teachers in the autonomy-supportive cluster also mentioned some controlling strategies (11 and $14 \%$ of their statements coded as strategies, respectively; see also Fig. 1). In line with previous research (e.g. Reeve 2009), teaching strategies were thus

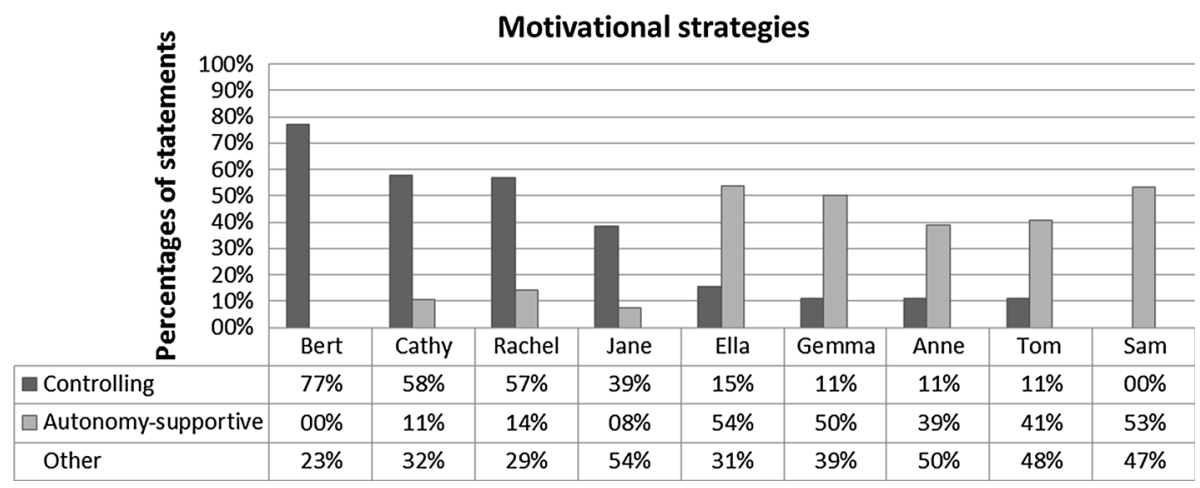

Fig. 1 Percentage of controlling and autonomy-supportive strategies per teacher 
found to vary from autonomy-supportive to controlling. Even though literature suggests that autonomy-supportive strategies are more favourable for student outcomes, all teachers except Sam reported using some controlling motivational strategies (varying from 11 to $77 \%$ of statements), such as using extrinsic rewards and directing students without providing choice or rationale.

\section{What are teachers' personal beliefs towards autonomy-supportive and controlling motivational strategies and how do these vary for teachers with different self-reported motivational strategies?}

A total of 103 statements (7-16 statements per teacher) referred to teachers' beliefs regarding autonomy-supportive versus controlling teaching strategies. Statements in which teachers expressed a preference towards any aspect of autonomy-support, or an opinion that students would benefit from such an aspect, were coded as autonomy-supportive. This was the case for $54 \%(n=56)$ of statements, $24 \%(n=25)$ of which were coded as controlling and $21 \%(n=25)$ as 'other'. Table 3 shows the percentage of statements expressing a belief towards autonomy-supportive or strategies separately for the two clusters: the teachers who reported mainly autonomy-supportive motivational strategies and the teachers who reported mainly controlling strategies.

As expected, teachers in the autonomy-supportive cluster more frequently expressed beliefs in favour of autonomy-support (66\% of statements referring to beliefs) compared to the teachers in the controlling cluster (37\%). Ella (autonomy-supportive cluster), for example, believed that students become motivated when they feel responsible and when the rationale for what they are learning is explained:

[I think it's motivating] when you give them the feeling that they are responsible, that they are engaged with the learning materials. If you'll tell them, already during instruction, why they are learning this. And because of that, they want to learn it, not because they have to (Ella).

Likewise, teachers in the controlling cluster more frequently expressed beliefs in favour of control (44\% of their belief-statements) compared with the teachers in the autonomysupportive cluster $(11 \%)$. It is however surprising to note that, even for teachers in the controlling cluster, less than half of the beliefs that they expressed included a preference for control. Moreover, they mentioned a preference for control almost as frequently as a preference for autonomy-support (44 vs. $37 \%$ of their statements), while teachers in the autonomy-supportive cluster mostly expressed autonomy-supportive beliefs and less controlling beliefs (66 vs. $11 \%$ ). A more detailed examination of the beliefs expressed by each teacher is depicted in Fig. 2. The four teachers on the left are teachers in the

Table 3 Percentage of beliefs of teachers with autonomy-supportive and controlling strategies

\begin{tabular}{llll}
\hline Beliefs & \multicolumn{2}{l}{ Cluster (practices) } & \\
\cline { 2 - 4 } & Autonomy-supportive (\%) & Controlling (\%) & Total (\%) \\
\hline Autonomy-supportive beliefs & 66 & 37 & 54 \\
Controlling beliefs & 11 & 44 & 24 \\
Other/mixed & 23 & 20 & 21 \\
\hline
\end{tabular}




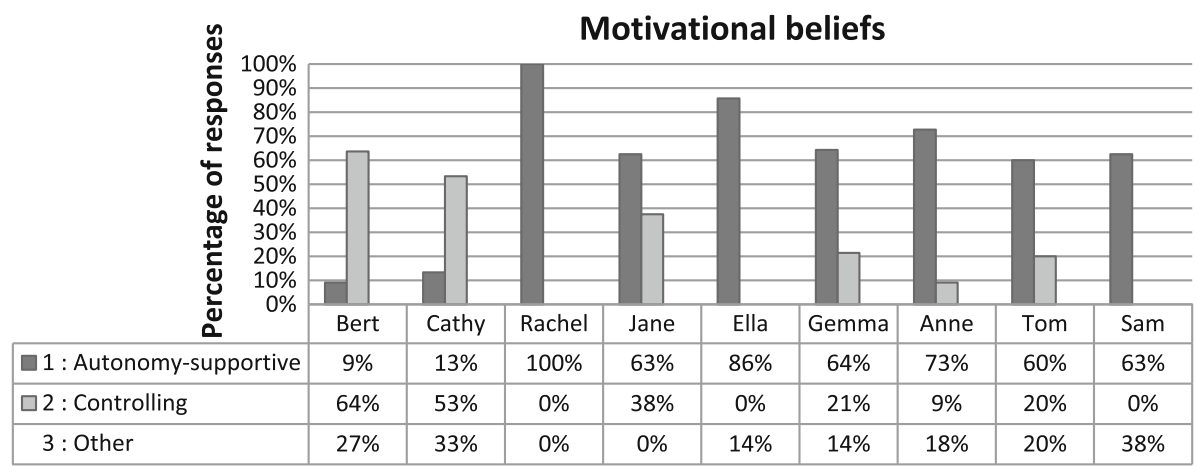

Fig. 2 Percentage of controlling and autonomy-supportive beliefs per teacher

controlling cluster, and this cluster shows great variety in personal beliefs. Bert and Cathy seem very much in favour of controlling strategies, whereas Jane and especially Rachel appear to be much more in favour of autonomy-supportive teaching. As mentioned, most of Jane's strategies were classified as 'other' and were often in between autonomysupportive and controlling practice. Her beliefs were more in favour of autonomy-support, yet a substantial proportion of her beliefs (38\%) indicated a preference for control. It could be that these beliefs-even though they were mentioned less frequently than beliefs in favour of control-explain her controlling strategies. When asked about other reasons behind her strategies, Jane found it hard to name other factors and did not seem to think very consciously about why she teaches in certain ways. Because she did not seem very aware of reasons behind her strategies, it is unclear whether her beliefs or other contextual factors accounted for her strategies. Rachel mentioned contextual factors as the main reason for the discrepancy between her strategies and beliefs. This is discussed more elaborately in later sections. For the five teachers in the autonomy-supportive cluster, their beliefs seemed much more aligned with their strategies.

According to Reeve (2009), one of the reasons why controlling motivational strategies are common is that many teachers have personal beliefs favouring such strategies. This indeed seemed to be the case for Bert and Cathy, but not for Rachel or Jane. Rachel, in particular, expressed very clear preferences towards autonomy-supportive motivational strategies, stating the importance for students to be responsible for their own learning and the importance of creating relevant and authentic learning experiences:

I would love it if we had corners in class, like a real 'fractions corner' and that it would be like: 'Go ahead, there's a pizza lying there' or 'Go ahead and cut this pancake today'. They would be interested in what is lying there and then start to think 'Aha, you can divide it in four pieces' and they would suddenly get it (Rachel).

In contrast, Bert and Cathy expressed preferences towards a more controlling teaching style:

The teacher decides. A rule is a rule, simple! (Bert)

I believe that they are really motivated by grades. They want tests and grades (Cathy). 
Another reason besides personal preferences for teachers to resort to controlling motivational strategies, according to Reeve (2009), is that many teachers confuse structure and control, and they hold the personal belief that they need to be directive or emphasise external rewards to provide students with sufficient structure. This ambiguity between structure and control can come about as structure can be delivered in both controlling and autonomy-supportive ways (Jang et al. 2010; Reeve 2009; Sierens et al. 2009). In a few teacher statements $(n=12)$ that were indicative of a preference for controlling strategies, structure and control indeed appeared to be entangled. This was found for teachers from both clusters, although most frequently among the controlling teachers:

You're not going to offer ten strategies to the weaker students; they'll crash. They have to be told one way, very directive. You'll do this, this fits you (Tom).

In the statement above, Tom prefers to limit the choices of his weaker students to provide them with structure, but Tom provides this structure by directing students without offering a rationale. A few statements $(n=5)$, especially of teachers in the autonomy-supportive cluster, report more autonomy-supportive ways of providing structure:

Some children, you'll keep them closer, because you know that's what they need.

You'll talk to them about 'what steps are you taking', but that really depends on their level (Anne).

To summarise, although there were a few statements referring to autonomy-supportive ways of providing structure, controlling ways of providing structure seemed more common for teachers in both clusters.

\section{What factors from below do teachers experience and how do these vary for teachers with different self-reported motivational strategies?}

Teachers were asked to describe the characteristics of their student population. Some teachers in the autonomy-supportive cluster (Ella, Sam), who described their students as being from middle-class to upper-class families, were positive about their students' abilities, while others (Tom, Anne) mostly emphasised differences within the classroom:

On average, these are children with highly educated parents, have high social status absolutely.... What you notice is that, when children come from a family where mom and dad went to college, they are people who perceive life in a different way. They are more explorative, more philosophically oriented (Sam).

You have the extremes. And well, some are average, some are... Some are just doing fine, others tend to fluctuate, some do well, and others are below average. Well, it differs (Tom).

In contrast to the other autonomy-supportive teachers, Gemma described that she was dealing with a more at-risk student population because she had been assigned a class that was known to be difficult:

When they came in, their achievement was low, a difficult group.... Difficult children, a lot of bullying, bad results. Almost beat the... out of each other, so to speak (Gemma). 
Except for Jane, who described her student population as average, the other three teachers in the controlling cluster (Rachel, Cathy and Bert) considered their student population to be at-risk, indicating that their students were either of low ability, were from a disadvantaged background, or had behavioural difficulties:

Their socio-emotional behaviour was like... Let's just say, it was pretty bad. That's why we decided to seat the students individually, because they were attacking each other with pencils and scissors (Rachel).

This neighbourhood is socially pretty weak. The nickname of this neighbourhood is 'valley of tears', which says enough.... A lot of people from socially disadvantaged backgrounds came here. The number of ethnic minority children at this school is quite large. Those people bring their own culture, their own way of life. Doing things by themselves is not as well developed here (Bert).

Especially when there were many ethnic minority students in the class and when there were few opportunities for these students to come into contact with Dutch children-which was especially the case in Cathy's class which consisted of only ethnic minority studentsstudents' language ability levels were considered problematic:

They live in this neighbourhood, where they have a lot of family. They visit each other but don't have any contact with Dutch children.... If you ask them to read a text and indicate which words they don't know, they'll give you a huge list. You think, o my, I didn't expect there to be so many. So, when you tell them that you want them to read the text and answer the questions by themselves, you know in advance that there's no use. They just don't know enough (Cathy).

In Fig. 3, teachers' perceptions of their student population are summarised. An interesting pattern thus emerged with most of the autonomy-supportive teachers perceiving their classrooms in more positive ways (with regard to ability level, behaviour, motivation) or indicating that their students were from more privileged backgrounds in comparison to the controlling teachers who described their students to be more at-risk.

An interesting exception to this pattern was Gemma who described her students to be atrisk in terms of ability levels and behaviour when they first entered her class, yet she

\begin{tabular}{lcc}
\hline & \multicolumn{2}{c}{ Cluster } \\
\cline { 2 - 3 } & Controlling strategies & $\begin{array}{c}\text { Autonomy-supportive } \\
\text { strategies }\end{array}$ \\
\hline $\begin{array}{l}\text { Negative perceptions of student ability, } \\
\text { background characteristics, behaviour } \\
\text { and/or motivation }\end{array}$ & Cathy & Gemma \\
$\begin{array}{l}\text { Average perceptions of student } \\
\text { population or focus on within-group } \\
\text { differences }\end{array}$ & Rachel \\
$\begin{array}{l}\text { Positive perceptions of student ability, } \\
\text { background characteristics, behaviour } \\
\text { and/or motivation }\end{array}$ & Tom \\
\hline
\end{tabular}

Fig. 3 Teachers' perceptions of student population by cluster 
reported a teaching style that could be considered autonomy-supportive. Gemma explained that the characteristics of her students did not determine her motivational strategies. In her opinion, the characteristics of the classroom population do not have to define motivational strategies, as long as sufficient structure is offered:

For years now, I have been the grade six teacher at this school. So, you hear that [difficult] group is coming. Well, I actually did not care about that from day one. Yes, well, I do of course, but you try to shape that, to work on that, and results are shooting up.... You have to be consistent and strict... That's when they can learn by themselves or together (Gemma).

Hence, Gemma considered the at-risk characteristics of her group as something that could be turned around. On the contrary, most controlling teachers (Bert, Cathy, Rachel) explicitly expressed that their students lacked the characteristics necessary for autonomysupportive teaching and considered this to be a given. Perceptions of their students' background and abilities were indeed described as one of the main reasons behind their controlling motivational strategies:

Most of the students cannot handle responsibility.... Responsibility is something far out of reach. I doubt whether these children will ever develop that. They don't even learn that at home (Rachel).

Some are like 'okay, I can decide for myself and not everything gets checked? Oh, then I'll just say I've finished. Fine!' They see it is a perfect way to get away with it. Well, then you'll be like, maybe it's a process of learning for them too, but it's not exactly what we envisioned.... A bit too loose and independent and they don't know how to handle freedom (Cathy).

According to Pelletier et al. (2002), teachers who perceive their students as unmotivated are more likely to rely on controlling motivational strategies. In addition to motivation, it seems that, when the teachers in this study perceived that their class included many lowability, low-SES, ethnic-minority or behaviourally-difficult students, they also experienced significant factors from below that pressured them towards controlling teaching methods. For example, Cathy felt that her class, which consisted of only ethnic minority students with Dutch as their second language, had such severe delays in language and other areas that she had to resort to controlling motivational strategies:

They lag behind in so many areas that you just pump as much information into them as possible.... They'll drown when they have to do anything by themselves. It's like 'I don't know' or 'I don't get it' (Cathy).

Interestingly, both Cathy and Bert had experiences with more autonomy-supportive motivational strategies. Based on these previous experiences, and what they believed would best suit their student population, both Cathy's and Bert's schools changed to more controlling strategies, which was something with which both teachers seemed to agree:

We used to be a Jenaplan school.... But the school population cannot handle it. Many children are not used to working independently. So we abandoned that Jenaplan idea a couple of years ago (Bert).

Before, we intentionally introduced independent learning, planning their own work... For many students, it did not lead to the results for which we had hoped because they don't seem to pick up on it. So now there was a conscious decision that, in this last year, we would try to cram as much into them as possible and hope that 
they'll reach a nice level. And working independently, how useful it may be, it's not a priority. Well, at least they've worked with it... The choice really was 'the teacher decides and the students have to follow' (Cathy).

On the contrary, after some negative evaluations by the inspection, Rachel was among a group of teachers hired specifically to implement autonomous teaching methods to improve results. But even though Rachel personally strongly favoured autonomysupportive teaching methods and felt supported by her school administration, she experienced difficulties in implementing that with her current class:

We hope to work towards [more independent learning], but we are very realistic. We don't think we'll ever reach the same level as in our old school (Rachel).

Like Cathy and Bert, Rachel often felt that she could not use autonomy-supportive motivational strategies with her students, suggesting that these controlling teachers felt severe pressure from factors from below. For Bert and Cathy, who preferred controlling ways of teaching, these factors aligned with their personal beliefs but, for Rachel, who preferred more autonomy-supportive methods, these factors from below were the main reason why she relied on controlling strategies. Anne, from the autonomy-supportive cluster, had previously worked at a more disadvantaged school and described being more controlling with those students. She felt that her current student population with more privileged backgrounds was more suited to autonomy-supportive teaching methods than the students at her previous school:

Last year, I taught at... an "educational opportunities school". The majority had ethnic minority parents or were from unstable homes.... You have to adjust to that.... With the kids I have now, I can let them work independently, just because I see that they can do that and they are able to manage that. I just have to check, support them and guide them. And if I look back at last year, that was not possible. I really had to take them by the hand, keep a close eye on them, and just tell them what to do all the time (Anne).

Especially Bert, Cathy and Rachel considered their students to be an at-risk group, but they also experienced additional pressure from factors from below from individual students who were perceived to be even lower in ability or motivation or more difficult in behaviour, resulting in more controlling, extrinsically-orientated motivational strategies. In the case of Bert, who already described his own overall strategies as rather controlling, it appeared that, when he experienced additional factors from below, he became even more controlling, even to a point where harsh strategies, sometimes even involving students receiving penalties in front of their peers, were mentioned:

...sometimes it works best to motivate [students] in a harsh way. By really having a go at them. Take, for example, this one boy. I really had a go at him in class, while the whole class was there. I got really angry at him, because he point-blank refuses to hand in his assignment.... For some students, that motivates (Bert).

Most of the other teachers (Jane, Tom, Ella, Sam, Anne) did not mention factors from below that referred to their whole class, but all of them experienced differences within their classes that affected their motivational strategies. In their experience, some students in their class, mostly those lower in ability, less motivated or more difficult in behaviour, needed to be offered more structure than other students in order to motivate them. This was mostly offered in controlling ways: 
We focus very much on 'learning to learn'. Our textbooks are also like that. For some students, that's difficult. I'll just tell them 'This is how you must do it', or otherwise they'll get confused. They barely understand one approach and then something else comes up, that confuses them.... I offer multiple strategies, that's just in the textbooks, and you'll advise those children just to pick that one and forget about the others. Other children are able to do that, and they don't find that difficult (Jane). With learning stuff, it's hard [to motivate him]. But if you say 'Come on, then you can go to play soccer outside for ten minutes', then he might go on for a bit (Ella).

In contrast, only Sam and Tom seemed to have found ways to motivate their at-risk students in more autonomy-supportive ways, such as appealing to students' own responsibility or addressing their interests:

$\mathrm{He}$ is almost impossible to motivate. We'll try every trick in the book to get him involved. We try to relate to his interests. For example, because he is crazy about the Muppets and making puppets, he can write a story about the Muppets. He loves Alice Cooper, and so we did that with music lessons (Sam).

That unmotivated student, I talk with him. What is going on? Why is that? And also address it: Okay, here we are, I'd like to see change. So you'll know what I want, how are you going to do that? (Tom)

In all, the paragraphs above seem to suggest a pattern that indicates that teachers who perceive their class as more at-risk find controlling motivational strategies more suitable for those students. This corresponds to research by Solomon et al. (1996) that suggests that teachers at more disadvantaged schools are more inclined towards more controlling ways of teaching. Moreover, when teachers considered individual students within their class to be at-risk, they found controlling motivational strategies more suitable for those students, feeling that not all students have similar needs for autonomy or that some students lack the skills necessary to handle any autonomy.

Another issue emerged during the interviews when teachers were asked about how factors from below related to their teaching strategies. It was found that teachers who perceived their students as more at-risk experienced a greater need for relatedness from their students. According to SDT, students have an innate need to feel cared for, to feel a sense of belonging, and to form strong and enduring interpersonal relationships with others, and this need has to be fulfilled in order for students to be intrinsically motivated (Stroet et al. 2013). Accordingly, most teachers (Ella, Tom, Gemma, Rachel, Bert and Cathy) talked about the crucial importance of creating a good relationship with their students and creating a positive learning climate in order to be able to motivate students:

They only learn when they are in a nice environment. Nice is nice. Just having a good atmosphere and everybody is themselves.... You got to have that flair of teaching, being a fun teacher. I'll only have to do this [blinks] and they'll do everything (Gemma).

Especially those teachers who considered their classroom population to be at-risk emphasised the importance of relatedness (Rachel, Cathy, Gemma and Bert). It is important to note that this also refers to self-reported strategies. Especially in the case of Bert, one might wonder whether he actually succeeded in creating a good relationship with his students given his harsh strategies. However, regardless of whether or not teachers succeeded in creating a warm relationship with their students and between students, it 
appeared that to them that a high level of control went alongside a high level of relatedness. Several reasons could account for that. Teachers with a more controlling teaching style also could focus more on relationships to compensate, because they might feel that learning activities are not intrinsically motivating to students. Establishing good relationships could be more important under such conditions:

Some students just learn for me. Because the teacher has got to have a high grade for the inspector, that's what I'll work for... I build a good relationship with them. The jokes I pull, the things we are able to say to each other... Because of that, they are more motivated to do the work (Bert).

They like to relax in between and just to talk, we make time for that. Like 'guys, who has something nice to talk about?' or 'Has anything happened?' and, if somebody has a story, we make time for that or just for a joke. And after that, it's 'Let's go again! Back to work!' (Cathy)

Moreover, creating a warm classroom climate might be more urgent and a bigger challenge to teachers with more difficult classrooms. Because teachers with more difficult classes have to invest more effort in establishing good relationships with students, they might focus more on supporting students' relatedness:

That bond that I feel with them, especially now... The first three weeks was a battle. That bond had to develop, but now I just feel it's coming from both sides. When I'm enthusiastic, they are (Rachel).

Finally, teachers with students from more disadvantaged backgrounds seemed to experience a greater need for relatedness from their students, as illustrated below:

You just feel that this student is all alone. At the beginning of the year, he was a real bully... but that totally turned around. I feel as if he has to do everything by himself, all alone.... The first thing that he does in the morning is wave until I see him. Just now he came in for his football but, without the ball, he would've been here too. [He is] just looking for contact. Well, if I can be the safe haven in his rough life, I'm happy to do that.... And there are more students... (Rachel)

The teachers in our sample who considered their students to be an at-risk population (Bert, Cathy, Rachel and Gemma) seemed to experience a greater need for relatedness and addressed this by focusing more on establishing a good relationship and a pleasant classroom atmosphere. Students from more disadvantaged backgrounds could feel a greater need to establish warm and caring relationships with their teachers. Most teachers in the autonomy-supportive cluster did not mention building a good relationship with their students and among students as a way of motivating them. This could indicate several things. First, it could be that, for their students, who are often from more privileged homes, it might not be so critical to find warmth and care outside the home. Second, these teachers might not consider fostering good interpersonal relationships as a necessary condition for students to become motivated. Third, it is also possible that relatedness is taken for granted by these teachers. Fourth, it could also be that relationships with their students are already quite good in these classrooms. Teachers therefore might focus more on issues that they consider to be more urgent for their population. 


\section{What factors from above do teachers experience and how do these vary for teachers with different self-reported motivational strategies?}

As discussed in the previous paragraphs, factors from below were important reasons for controlling strategies for most teachers in the controlling cluster (Bert, Cathy and Rachel). The other controlling teacher, Jane, mentioned factors from above as a reason for controlling strategies. She expressed that controlling strategies are sometimes more effective when performance standards need to be reached:

It would be good if lessons related more to students, but that has to fit within the allocated time... But, like today, it cannot be all fun and games and sometimes there are rules, and that's it (Jane).

Not only Jane, but all nine teachers, discussed factors that could invoke pressure, such as meeting performance standards set by the inspectorate, high-stakes testing, having to follow textbook methods used at the school, or adapting to the broader school educational philosophy. The degree to which these factors were also experienced as pressuring, conflicting with personal beliefs, or affecting their motivational strategies differed between teachers. Especially the autonomy-supportive teachers experienced clear friction between these factors from above and their personal beliefs:

I believe that authentic learning experiences are really important. So, I try to invest time and effort in that, but daily reality shows that it's not always possible, because you're restricted to certain teaching methods or certain standards set by the inspectorate (Sam).

According to SDT, high stakes testing can undermine students' autonomous motivation and promotes a controlling instructional approach (Ryan and Weinstein 2009). As such, testing is often mandatory, and teachers are held accountable for the outcomes, it can be one of the main reasons for teachers to rely on controlling teacher strategies (Reeve 2009). Across both clusters, teachers were forced to administer high-stakes tests, but most teachers did not experience this as pressuring. In fact, it was mostly considered to be a helpful way to monitor student progress:

I think it [testing] is important. You keep track of a student, how he or she is doing (Sam).

We use these tests to monitor their progress, see where there are gaps in their knowledge, where extra help is needed. And results are very clear for parents (Cathy).

We talk about [test results] with the kids... We have to, partly because of pressure by the inspector. But well, I don't think it's a bad thing (Bert).

According to the literature, high-stakes testing and rewarding students with grades are believed to undermine students' intrinsic motivation (e.g. Ryan and Weinstein 2009), but their impact tends to depend on the way in which they are delivered (Deci and Ryan 1985). Gemma perceived formal assessment to be a pressure from above, but used the tests in such a way that students could reflect on their own progress. Hence, she used the external outcomes of formal testing, the grades in an autonomy-supportive way:

We are obliged to do formal assessments three times a year. It gives an impression. Fine. I'll look at it. I'll have to look at it. But, if it were up to me, we'd be throwing out all of those tests. I know it already.... Children reflect on their progress, and ask 
why did they get a ten on that test and four on the other one? It's because of this or because of that.... Children have to look at themselves and progress through that. My children know that pretty well, and ask why they are I struggling with language and succeeding at mathematics? (Gemma)

Ella also considered formal assessment to be a pressure from above, dealing with that by putting a greater emphasis on alternative ways of evaluating student progress:

We have the children write us [the teachers] a letter and we respond to it. We mention a couple of topics that need to be addressed in the letter: 'How do you feel in the class, who do you like to spend time with, what are you good at, and what would you still like to learn?'. We have a sort of registration book, with a lot of things in it. Which books have you read, what presentations did you do? It also contains their achievement outcomes. Their letters are also included in that (Ella).

Across both clusters, teachers mostly felt comfortable with the educational concept, policies or textbook methods used at their schools. Teachers in the autonomy-supportive cluster were mostly working at rather innovative schools, supporting autonomy-supportive motivational strategies. As such, factors from above can also steer teachers towards more autonomy-support.

Our teaching methods already connect to students' worlds pretty well. But, other than that, you think of extra examples or have it come from the kids (Anne).

Well, group work is motivating for example.... That's what's really appealing about the BAS project [reform trajectory the school is in] (Gemma).

We are using textbook method M. That's with real examples. And with language, we use method P. It's not like a method; it's playful and involves a lot of doing, experiencing. So they learn, not just by books, but you can really connect to children (Ella).

Cathy and Bert were working at schools supporting controlling ways of teaching because their school administrations also felt that controlling ways were more suitable to their student population:

We are doing 'modelling', which is part of a trajectory we have been doing for a while. It means that we show the best way to perform a task. Here is a text, what are you looking at? No, you don't just start reading it, you first check the title (Bert).

Rachel personally preferred an autonomy-supportive teaching style which she was supported in developing at her school. Her difficulties in actually realising more autonomysupportive ways of teaching were mostly attributed to factors from below.

Overall, national standards, high-stakes testing or the textbook methods were sometimes considered pressuring, especially by the autonomy-supportive teachers, but most teachers also found ways to deal with these pressures that corresponded with their beliefs. National standards, high-stakes testing or textbook methods were not considered pressuring factors by most teachers in the controlling cluster. In both clusters, because teachers felt supported by their schools to teach according to their personal beliefs, the educational concept of the school was not considered a pressure by any of the teachers in our sample. 


\section{Discussion}

The purpose of this study was to gain a more thorough understanding of the reasons behind teachers' motivational strategies, because teachers' motivational strategies shape students' learning environment. Two clusters of teachers were distinguished. One cluster comprised teachers who mainly reported autonomy-supportive strategies and the other cluster comprised teachers who reported mainly controlling strategies. The underlying reasons reported for autonomy-supportive and controlling strategies are summarised in the model displayed in Fig. 4. For the most part, teachers' personal beliefs were aligned with their self-reported strategies. Teachers who held personal beliefs in favour of autonomy-support believed that their students would benefit most from autonomy-supportive strategies and that these beliefs were used to justify use of autonomy-supportive strategies. In addition, factors from above, such as the educational concept of the school, were mentioned as additional reasons for autonomy-supportive strategies. Reasons for use of controlling strategies, however, were more diverse. Although some teachers held personal beliefs in favour of controlling strategies, others reported use of controlling strategies despite personal beliefs in favour of autonomy-supportive strategies. Factors from above influenced tendencies towards controlling strategies for some of the teachers, especially negative perceptions of students' ability, background, motivation or behaviour. For most teachers in the cluster with mostly controlling strategies, factors from below also included negative perceptions of whole-class characteristics. These teachers felt that their class lacked the abilities necessary for autonomy-supportive teaching. In addition, teachers in both clusters experienced such factors from below and referred to negative perceptions of individual students, which they identified as a reason for using more controlling strategies.

Furthermore, Fig. 4 also shows another theme that emerged during the study and that was the role of interpersonal relatedness. Teachers who reported more controlling strategies and who perceived their classroom population as more at-risk felt a greater need to

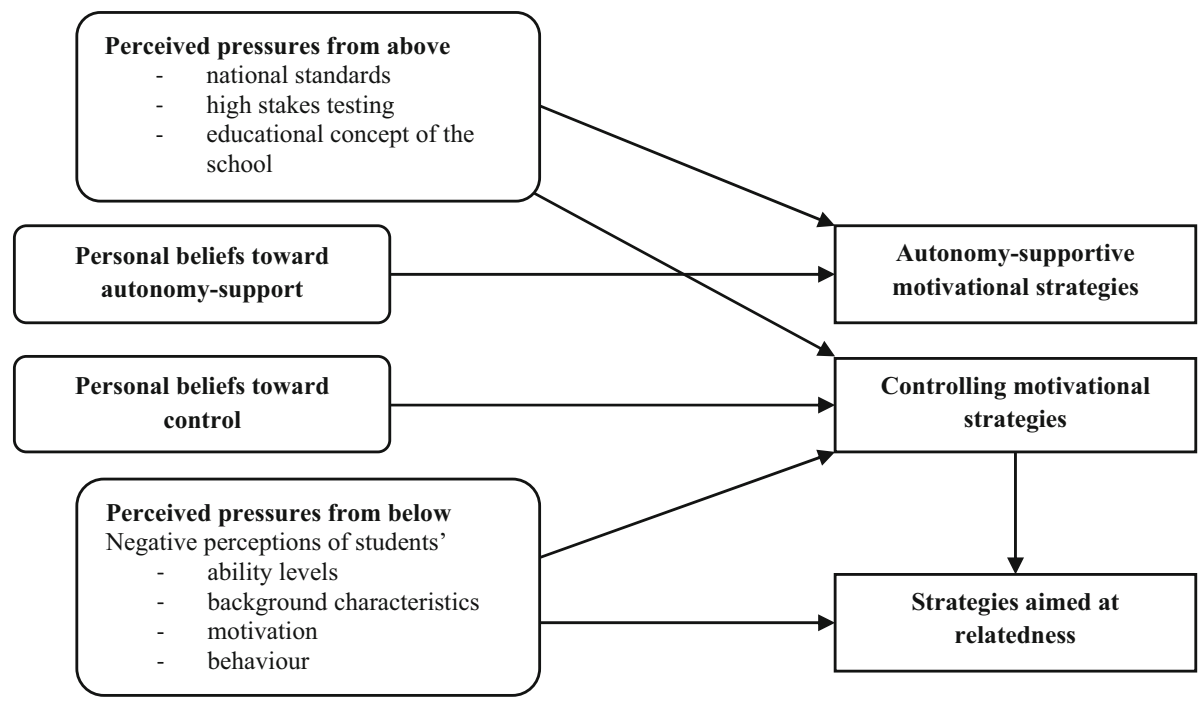

Fig. 4 Conceptual model showing underlying reasons for autonomy-supportive and controlling motivational strategies 
create a strong affective bond with their students and a warm classroom climate. These outcomes contribute to our understanding of the reasons underlying teachers' motivational strategies and how they try to create a motivating learning environment for their students. Below, a number of key issues that need further discussion are addressed.

\section{The crucial role of teacher perceptions of their students in explaining motivational strategies}

While previous literature has emphasised how factors from above can explain teachers' controlling motivational strategies (Niemic and Ryan 2009; Reeve 2009; Ryan and Weinstein 2009), the outcomes of the present study suggest that factors from below weigh more heavily for teachers. In many countries, teachers are faced with diverse student populations, and some schools are mostly populated by at-risk students (Bakker and Denessen 2011). A concerning finding of this study is that, especially when teachers considered their students to be at-risk (i.e. low-ability, unmotivated, difficult in behaviour or from disadvantaged backgrounds), they relied much more often on controlling strategies. They felt autonomy-supportive strategies were not suitable for motivating their students. Because this study was based on self-reports, more research is needed to examine whether autonomy-support is indeed less effective for at-risk students. Another explanation could be that these teachers are ill-prepared in providing adequate autonomy-support for these students.

All teachers indicated the importance of structure, especially for at-risk students. Structure can be delivered in either autonomy-supportive or controlling ways, but previous literature has suggested that many teachers confuse providing structure with control (Reeve 2009). Accordingly, in this study, teachers reported mostly controlling ways of providing structure for at-risk students. Even autonomy-supportive teachers described being more controlling with the at-risk students in their class. As autonomy-supportive strategies are believed to encourage intrinsic motivation (Jang et al. 2010; Vallerand 1997), increase deep learning strategies and promote self-regulated learning (Deci et al. 1991; Vansteenkiste et al. 2004, 2006), the controlling strategies used by these teachers could thus prevent at-risk students from actually becoming motivated and independent learners. This could actually cause already-existing differences in motivation, learning and achievement to be exacerbated. This is especially concerning as previous research suggests that teacher perceptions of their students can be based on biased beliefs rather than actual information about students' ability levels (van den Bergh et al. 2010).

Within teacher expectancy literature, it has been suggested that teachers' perceptions of individual students can explain a wide variety of teaching behaviours (Rosenthal 1994). Accordingly, the outcomes of the present study show that teachers are more controlling of students who they perceive to be more 'at-risk'. Moreover, it was not only perceptions of individual students that mattered, but the extent to which teachers adopt an autonomysupportive or controlling teaching style in general seemed to depend on their perceptions of their student population as a whole.

Our results also suggest that the model presented in Fig. 4 could be cyclical in nature. Teachers' prior experiences appeared to inform their personal beliefs and preferences towards either controlling or autonomy-supportive motivational strategies. Prior experiences of success or failure of their motivational strategies with certain student populations seemed to confirm or dismiss previously-held beliefs about the extent to which they felt that autonomy-supportive motivational strategies were suitable for their students. Teacher perceptions of their students, as well as their prior experiences with other student 
populations, thus seem very important to take into consideration when examining teachers' motivational strategies.

\section{Are students' needs universal?}

SDT suggests that students' needs for autonomy, competence and relatedness are universal needs that apply to all students (Reeve et al. 2004a, b; Deci and Ryan 1985), but most teachers in this study expressed the view that students can differ in the strength of their needs. At-risk students were perceived to have less need for autonomy, but a greater need for relatedness in comparison to other students. Whereas SDT emphasises the disadvantageous effects of a controlling approach on students' motivation, teachers using controlling motivational strategies were often well intentioned, believing that such strategies suited their students' needs better. Teachers expressed the view that more controlling strategies actually nurtured the specific needs of their at-risk students. To them, this was an adaptive approach, based on their assumption that not all students had similar needs for autonomy.

Moreover, teachers in more disadvantaged classes were more concerned with the socioemotional climate of the classroom as they experienced a greater need for relatedness from these students for whom a good relationship with the teacher can act as a buffer to protect them from negative motivational outcomes for which they are more at-risk. In contrast to SDT that emphasises the universality of needs (Deci and Ryan 1985), Hamre and Pianta (2001) suggest that students from more disadvantaged backgrounds could have a greater need for relatedness. Especially for students from more disadvantaged backgrounds, school culture could be different from what they are accustomed to at home. A good relationship with teachers might be essential in preventing this disparity between the home and school environment from being harmful. Moreover, these students are at greater risk for disengagement and good relationships with teachers might have a preventative, 'buffering' effect (Hamre and Pianta 2001).

To the best of our knowledge, research on differences in need strengths is scarce. There are a few cross-cultural studies that have addressed the issue of universality, suggesting that the strength of students' needs could depend on students' background characteristics. Depending on parenting style, students could differ in the extent to which they are accustomed to dealing with autonomy. In cross-cultural studies, it is argued that autonomy is a value of Western, individualistic societies and that it might not be as beneficial to students who have a background from more collectivistic cultures (Kitayama et al. 2004; Markus and Kitayama 2010). Iyengar and Lepper (1999), for example, showed that more autonomy was associated with increased motivation of European-American children, while Asian children were more motivated when trusted authority figures made choices for them. Sheldon et al. (2001) showed that members from collectivistic cultures find relatedness more fulfilling than members from other cultures. Moreover, Deci et al. (2001) found that people from Bulgaria were less negatively affected by a controlling climate.

In all, the outcomes of these studies do not claim that people from some cultures or backgrounds lack the need for autonomy, competence or relatedness, but they do suggest that-in line with beliefs expressed by teachers in our study-there could be differences between students in need strength and different ways to meet those needs. The issue of differences in need strength has hardly been examined and, even though research shows overall positive effects of autonomy-support or relatedness (Stroet et al. 2013), that does not exclude the possibility that some students might benefit more than others. The views held by teachers also suggest that students' needs or the ways to fulfil them not only 
depend on their ethnicity or culture, but that these also could depend on other characteristics, such as ability levels, SES or behavioural characteristics.

\section{Interaction between control and relatedness}

Another interesting issue emerged from our study. The teachers in the controlling cluster thought that it was particularly important to create a warm classroom climate and to develop a good relationship with their students. Other studies have also shown that higher levels of control appear to go alongside higher levels of relatedness (Nichols 2006). The controlling teachers experienced a greater need for relatedness from their students, but they also indicated that they needed that bond to encourage students to engage in learning activities in which they might not autonomously want to engage. As controlling teachers rely more on extrinsic strategies (such as 'learning for the teacher'), a well-established affective relationship with their students thus could be more important. Abundant research has shown that students' affective relationship with their teacher (e.g. Cornelius-White 2007; Roorda et al. 2011) is crucial to their motivation. That could be especially so when teachers use controlling motivational strategies. None of the teachers in the controlling cluster thought that their students felt controlled or pressured, particularly because of the strength of the teacher-student relationship. According to these teachers, this indicates that, when students experience an affectionate bond with their teacher, yet experience controlling strategies, they might not perceive these as frustrating their needs. A certain degree of control, when delivered in a highly-affectionate way, could perhaps not necessarily undermine students' motivation. Although SDT has not specifically addressed the issue of potential interactions between relatedness and control, this has been described in interpersonal theory (Leary, 1975 in Wubbels and Brekelmans 2005). According to this theory, a teaching style which involves both intermediate levels of control and affiliation is most beneficial for students' engagement.

\section{Implications for teacher education}

This study also has implications for teacher education. First, the study shows that teachers find it harder to teach at-risk students in autonomy-supportive ways. This highlights the need for pre- or in-service teachers to develop understandings about motivating students in classrooms with diverse student populations. Second, teacher education programmes have the potential to provide experiences for which pre- or in-service teachers can examine factors that influence their beliefs about students (e.g. SES, ability levels, ethnic background). Building awareness of how such beliefs are formed and influence teacher behaviour could provide a grounding with which future teachers can exercise some caution in their own practice.

\section{Future directions}

Before discussing implications for further research, a number of limitations of the present study need to be addressed. First, only teachers' self-reported motivational strategies were taken into account. Although leading to a deeper understanding of teachers' experiences, self-reports might not fully reflect the actual motivational strategies that they employ in their classrooms. Future research could address this by including classroom observations of teacher behaviours. Also, specific characteristics of the Dutch educational context and the 
small sample size-which however represented a broad diversity of teaching strategies and school populations - could limit the generalisability of our findings. Further research is needed to examine whether similar patterns can be observed across different educational contexts. Because of the exploratory nature of our research, only a small sample of teachers was included. Larger studies are needed to further confirm the framework that resulted from this study. Nevertheless, the outcomes of the study provide a useful framework that can serve as a starting point for further research and point to a number of important implications for future research and practice.

The outcomes show that theoretical notions and teacher views of how to create a motivating learning environment for students are clearly distinct. The beliefs held by teachers suggest that controlling motivational strategies-for some students and under certain conditions-might not be as harmful as suggested in literature. As this study focused on teacher perceptions, more research is needed to unravel whether different student characteristics actually relate to the strength of students' needs and the ways in which teachers can meet students' needs. More specifically, the hypothesis that at-risk students have a stronger need for relatedness and that their need for autonomy is less strong needs to be examined in future research.

Moreover, further research is especially needed to uncover how socio-emotional aspects of the teacher-student relationship might interact with controlling motivational strategies and whether control-when delivered in a way that students' need for relatedness is supported-is less detrimental for students' autonomous motivation than often assumed in literature. It thus seems important to consider not only what motivational strategies teachers use to shape the learning environment, but also how these strategies are enacted.

Acknowledgments This research was supported by a grant from the National Scientific Organization of the Netherlands (NWO).

Open Access This article is distributed under the terms of the Creative Commons Attribution 4.0 International License (http://creativecommons.org/licenses/by/4.0/), which permits unrestricted use, distribution, and reproduction in any medium, provided you give appropriate credit to the original author(s) and the source, provide a link to the Creative Commons license, and indicate if changes were made.

\section{Appendix}

See Table 4.

Table 4 Vignettes describing traditional and innovative teachers

\begin{tabular}{lll}
\hline & Traditional learning & Innovative learning \\
\hline $\begin{array}{l}\text { Collaborative } \\
\text { learning }\end{array}$ & $\begin{array}{c}\text { Teacher A mostly lets the children work } \\
\text { individually. Whenever they work in } \\
\text { together, it is usually to work on a short } \\
\text { assignment. Everybody in the group } \\
\text { receives the same grade for a group } \\
\text { assignment }\end{array}$ & $\begin{array}{l}\text { Teacher B lets the children work in } \\
\text { groups en collaboration is emphasized: } \\
\text { every student participates and is } \\
\text { responsible for the final group product. } \\
\text { Teacher B also discusses how to } \\
\text { collaborate: how to interact with each } \\
\text { other and how to solve problems if } \\
\text { those arise? Whenever an assignment is } \\
\text { finished every students is held } \\
\text { responsible for their own part }\end{array}$ \\
& &
\end{tabular}


Table 4 continued

\begin{tabular}{ll}
\hline & Traditional learning \\
\hline $\begin{array}{l}\text { Responsibility of } \\
\text { the learning } \\
\text { process }\end{array}$ & $\begin{array}{l}\text { Teacher B tells the students what to do } \\
\text { and when to work on which subject. }\end{array}$ \\
& $\begin{array}{l}\text { So, all students work together on the } \\
\text { same subject at the same time. Teacher } \\
\text { B usually starts the lessons in front of } \\
\text { the class and decides when students } \\
\text { have to finish something }\end{array}$
\end{tabular}

Innovative learning

In teacher A's class, students can plan for themselves when they want to work on which subject and on which assignment. So, not everybody works on the same subject at the same time. Students themselves are responsible for finishing their assignments in time. Students work with their own week schedule or planner. They often work independently and are allowed to make a lot of choices for themselves.

Assignment allow students to work on them for a prolonged period of time and to explore for themselves. The teachers helps when necessary

Authentic learning

In teacher A's class, the lessons such as calculations or spelling principles are often repeated so students can remember it well. Often, teachers learn principles or rules by heart

Focus on selfregulated learning and metacognition
Teacher B tells which assignments or tasks students should make and explains one approach. Afterwards, students practice that individually in their workbooks. Afterwards the teachers checks whether students' answers were correct or not

\section{Innovative assessment methods}

In teacher A's class, students often make standardized tests to determine their progress. The teacher keeps very well track of how students are performing in comparison to the national average, in order to identify students that are performing below average at an early stage. Students' get a report card with grades. This shows whether they are doing well in school
Teacher B uses a lot examples of situations that students are faced with outside of school and thus especially relevant to them. Sometimes, lessons take place outside of the school or people from outside the school come into the classroom to tell something. At teacher B's school a biology class is for example taught outside, or students are allowed to write papers about topics they want to learn more about

Teacher A spends a lot of time on how you study: how do you start an assignment, what steps do you follow, what is a smart approach, and how to reflect on a task? Students often correct their own work. Students can decide for themselves how to do an assignment, there are different ways possible and they find out what works best for them. Teacher A not only checks whether the answer was correct, but also reflects on how the students' task approach and encourages students to evaluate their own work and approach

In addition to tests, teacher $B$ lets students save their work in a portfolio to determine whether the learning has progressed. Teacher B discusses with students, for example based on their portfolio, where they are and what they can continue to work on 


\section{References}

Archambault, I., Janosz, M., \& Chouinard, R. (2012). Teacher beliefs as predictors of adolescents' cognitive engagement and achievement in mathematics. Journal of Educational Research, 105, 319-328.

Avalos, B. (2011). Teacher professional development in teaching and teacher education over ten years. Teaching and Teacher Education, 27, 10-20.

Bakker, J., \& Denessen, E. (Eds.). (2011). International perspectives on countering school segregation. Antwerp-Apeldoorn: Garant.

Cornelius-White, J. (2007). Learner-centered teacher-student relationships are effective: A meta-analysis. Review of Educational Research, 77, 113-143.

Deci, E. L., \& Ryan, R. M. (1985). Intrinsic motivation and self-determination in human behavior. New York: Plenum.

Deci, E. L., Ryan, R. M., Gagné, M., Leone, D. R., Usunov, J., \& Kornazheva, B. P. (2001). Need satisfaction, motivation, and well-being in the work organizations of a former Eastern Bloc country. Personality and Social Psychology Bulletin, 27, 930-942.

Deci, E. L., Spiegel, N. H., Ryan, R. M., Koestner, R., \& Kauffman, M. (1982). Effects of performance standards on teaching styles: Behavior of controlling teachers. Journal of Educational Psychology, 74, 852-859.

Deci, E. L., Vallerand, R. J., Pelletier, L. G., \& Ryan, R. M. (1991). Motivation and education: The selfdetermination perspective. Educational Psychologist, 26(3-4), 325-346.

Driessen, G., Sleegers, P., \& Smit, F. (2008). The transition from primary to secondary education: Meritocracy and ethnicity. European Sociological Review, 24, 527-542.

Eccles, J. S., \& Roeser, R. W. (2011). Schools as developmental contexts during adolescence. Journal of Research on Adolescence, 21, 225-241.

Eisenhart, M. A., Schrum, J. L., Harding, J. R., \& Cuthbert, A. M. (1988). Teacher beliefs: Definitions, findings, and directions. Educational Policy, 2, 51-70.

Fraser, B. J. (2012). Classroom environment. New York: Routledge.

Furtak, E. M., \& Kunter, M. (2012). Effects of autonomy-supportive teaching on student learning and motivation. The Journal of Experimental Education, 80, 284-316.

Hamre, B. K., \& Pianta, R. C. (2001). Early teacher-child relationships and the trajectory of children's school outcomes through eighth grade. Child Development, 72, 625-638.

Henderson, D. G., \& Fisher, D. L. (2008). Interpersonal behaviour and student outcomes in vocational education classes. Learning Environments Research, 11, 19-29.

Iyengar, S. S., \& Lepper, M. R. (1999). Rethinking the value of choice: A cultural perspective on intrinsic motivation. Journal of Personality and Social Psychology, 76, 349-366.

Jang, H., Reeve, J., \& Deci, E. L. (2010). Engaging students in learning activities: It is not autonomy support or structure but autonomy support and structure. Journal of Educational Psychology, 102, 588-600.

Jungbluth, P. (2003). The unequal primary school: Ethnicity, social environment, gender, concealed differentiation, educational opportunity and school effectiveness. Nijmegen: ITS.

Jussim, L., Eccles, J., \& Madon, S. J. (1996). Social perception, social stereotypes, and teacher expectations: Accuracy, and the quest for the powerful self-fulfilling prophecy. Advances in Experimental Social Psychology, 29, 281-388.

Jussim, L., \& Harber, K. D. (2005). Teacher expectations and self-fulfilling prophecies: Knowns and unknowns, resolved and unresolved controversies. Personality and Social Psychology Review, 9, $131-155$

Kitayama, S., Snibbe, A. C., Markus, H. R., \& Suzuki, T. (2004). Is there any "free" choice? Psychological Science, 15, 527-533.

Madon, S., Jussim, L., \& Eccles, J. (1997). In search of the powerful self-fulfilling prophecy. Journal of Personality and Social Psychology, 72, 791-809.

Mansfield, C. F., \& Volet, S. E. (2010). Developing beliefs about classroom motivation: Journeys of preservice teachers. Teaching and Teacher Education, 26(7), 1404-1415.

Mansour, N. (2009). Science teachers' beliefs and strategies: Issues, implications and research agenda. International Journal of Environmental and Science Education, 4, 25-48.

Markus, H. R., \& Kitayama, S. (2010). Cultures and selves. Perspectives on Psychological Science, 5, $420-430$.

Maulana, R., Opdenakker, M. C. J. L., den Brok, P., \& Bosker, R. J. (2012). Teacher-student interpersonal relationships in Indonesian lower secondary education: Teacher and student perceptions. Learning Environments Research, 15, 251-271.

McKown, C., \& Weinstein, R. S. (2008). Teacher expectations, classroom context, and the achievement gap. Journal of School Psychology, 46, 235-261. 
Miles, M. B., \& Huberman, A. M. (1994). Qualitative data analysis (2nd ed.). Thousand Oaks, CA: Sage Publications.

Nichols, J. D. (2006). Empowerment and relationships: A classroom model to enhance student motivation. Learning Environments Research, 9, 149-161.

Niemic, C. P., \& Ryan, R. M. (2009). Autonomy, competence, and relatedness in the classroom: Applying self-determination theory to educational practice. Theory and Research in Education, 7, 133-144.

Nolen, S. B. (2011). The role of educational systems in the link between formative assessment and motivation. Theory Into Practice, 50, 319-326.

Nurmi, J., Viljaranta, J., Tolvanen, A., \& Aunola, K. (2012). Teachers adapt their instruction according to students' academic performance. Educational Psychology, 32, 571-588.

Oakes, J. (1985). Keeping track: How schools structure inequality. New Haven, CT: Yale University Press.

Ogbuehi, P. I., \& Fraser, B. J. (2007). Learning environment, attitudes and conceptual development associated with innovative strategies in middle-school mathematics. Learning Environments Research, 10, $101-114$.

Pajares, J. (1992). Teachers' beliefs and educational research: Cleaning up a messy construct. Review of Educational Research, 62, 307-332.

Pelletier, L. G., Séguin-Lévesque, C., \& Legault, L. (2002). Pressure from above and pressure from below as determinants of teachers' motivation and teaching behaviors. Journal of Educational Psychology, 94, $186-196$.

Pintrich, P. R. (2004). A conceptual framework for assessing motivation and self-regulated learning in college students. Educational Psychology Review, 16, 385-407.

Raymond, A. M. (1997). Inconsistency between a beginning elementary school teacher's mathematics beliefs and teaching practice. Journal for Research in Mathematics Education, 28, 550-576.

Reeve, J. (2009). Why teachers adopt a controlling motivating style toward students and how they can become more autonomy supportive. Educational Psychologist, 44, 159-175.

Reeve, J., Deci, E. L., \& Ryan, R. M. (2004a). Self-determination theory: A dialectical framework for understanding socio-cultural influences on student motivation. In D. M. McInerney \& S. Van Etten (Eds.), Big theories revisited (pp. 31-60). Greenwich, CT: Information Age Press.

Reeve, J., \& Jang, H. (2006). What teachers say and do to support students' autonomy during a learning activity. Journal of Educational Psychology, 98, 209-218.

Reeve, J., Jang, H., Carrell, D., Jeon, S., \& Barch, J. (2004b). Enhancing students' engagement by increasing teachers' autonomy support. Motivation and Emotion, 28, 147-169.

Richardson, V. (2003). Preservice teachers' beliefs. In J. Rath \& A. C. McAninch (Eds.), Teacher beliefs and classroom performance: The impact of teacher education (pp. 1-22). Charlotte, NC: IAP.

Roorda, D. L., Koomen, H. M. Y., Spilt, J. L., \& Oort, F. J. (2011). The influence of affective teacherstudent relationships on students' school engagement and achievement. Review of Educational Research, 81, 493-529.

Rosenthal, R. (1994). Interpersonal expectancy effects: A 30-year perspective. Current Directions in Psychological Science, 3, 176-179.

Rosenthal, R., \& Jacobson, L. (1968). Pygmalion in the classroom. New York: Holt, Rinehart, and Winston.

Rubie-Davies, C. M. (2010). Teacher expectations and perceptions of student attributes: Is there a relationship? British Journal of Educational Psychology, 80, 121-135.

Rubie-Davies, C. M., Flint, A., \& McDonald, L. G. (2012). Teacher beliefs, teacher characteristics, and school contextual factors: What are the relationships? British Journal of Educational Psychology, 82, 270-288.

Ryan, R. M., \& Brown, K. W. (2005). Legislating competence: High-stakes testing policies and their relations with psychological theories and research. In A. J. Elliot \& C. S. Dweck (Eds.), Handbook of competence and motivation (pp. 354-372). New York: Guilford Publications.

Ryan, R. M., \& Deci, E. L. (2000a). Intrinsic and extrinsic motivations: Classic definitions and new directions. Contemporary Educational Psychology, 25, 54-67.

Ryan, R. M., \& Deci, E. L. (2000b). Self-determination theory and the facilitation of intrinsic motivation, social development, and well-being. American Psychologist, 55, 68-78.

Ryan, R. M., \& Weinstein, N. (2009). Undermining quality teaching and learning: A self-determination theory perspective on high-stakes testing. Theory and Research in Education, 7, 224-233.

Sheldon, K. M., Elliot, A. J., Kim, Y., \& Kasser, T. (2001). What is satisfying about satisfying events? Testing 10 candidate psychological needs. Journal of Personality and Social Psychology, 80, 325-339.

Sierens, E., Vansteenkiste, M., Goossens, L., Soenens, B., \& Dochy, F. (2009). The interactive effect of perceived teacher autonomy-support and structure in the prediction of self-regulated learning. British Journal of Educational Psychology, 79, 57-68. 
Solomon, D., Battistich, V., \& Hom, A. (1996). Teacher beliefs and strategies in schools serving communities that differ in socioeconomic level. The Journal of Experimental Educational, 64, 327-347.

Stroet, K., Opdenakker, M. C., \& Minnaert, A. (2013). Effects of need supportive teaching on early adolescents' motivation and engagement: A review of the literature. Educational Research Review, 9 , 65-87.

Tenenbaum, H. R., \& Ruck, M. D. (2007). Are teachers' expectations different for racial minority than for European American students? A meta-analysis. Journal of Educational Psychology, 99, 253-273.

Turner, J. C. (2010). Unfinished business: Putting motivation theory to the "classroom test". In T. Urdan \& S. A. Karabenick (Eds.), The decade ahead: Applications and contexts of motivation and achievement (Vol. 16B, pp. 109-138). Bingley: Emerald Group Publishing.

Turner, J., Christensen, L., \& Meyer, D. (2009). Teachers' beliefs about student learning and motivation. In L. J. Saha \& A. G. Dworkin (Eds.), International handbook of research on teachers and teaching (pp. 361-371). New York: Springer.

Vallerand, R. J. (1997). Toward a hierarchical model of intrinsic and extrinsic motivation. In M. P. Zanna (Ed.), Advances in experimental social psychology (Vol. 27, pp. 271-360). New York: Academic Press.

Van den Bergh, L., Denessen, E., Hornstra, L., Voeten, M., \& Holland, R. W. (2010). The implicit prejudiced attitudes of teacher relations to teacher expectations and the ethnic achievement gap. American Educational Research Journal, 47(2), 497-527.

Vansteenkiste, M., Lens, W., \& Deci, E. L. (2006). Intrinsic versus extrinsic goal contents in self-determination theory: Another look at the quality of academic motivation. Educational Psychologist, 41, 19-31.

Vansteenkiste, M., Simons, J., Lens, W., Sheldon, K. M., \& Deci, E. L. (2004). Motivating learning, performance, and persistence: The synergistic role of intrinsic goals and autonomy-support. Journal of Personality and Social Psychology, 87, 246-260.

Wubbels, T., \& Brekelmans, M. (2005). Two decades of research on teacher-student relationships in the class. International Journal of Educational Research, 43, 6-24. 